\title{
Potent inhibitory effect of alcoholic beverages upon gastrointestinal passage of food and gallbladder emptying
}

\author{
Anna Kasicka-Jonderko • Krzysztof Jonderko • \\ Małgorzata Bożek • Magdalena Kamińska • \\ Patrycja Mgłosiek
}

Received: 22 November 2012 / Accepted: 10 January 2013/Published online: 19 February 2013

(C) The Author(s) 2013. This article is published with open access at Springerlink.com

\begin{abstract}
Background and aims Current knowledge about the effect of alcoholic beverages on postprandial functioning of the digestive system is scarce and inconsistent. This study addresses their influence upon meal movement along the gut and meal-induced gallbladder emptying.

Methods Three examination blocks involved each 12 healthy volunteers. Ingestion of a solid $1485 \mathrm{~kJ}$ meal was followed by intake of $400 \mathrm{ml}$ beer $(4.7 \% \mathrm{vol}), 200 \mathrm{ml}$ red wine $(13.7 \% \mathrm{vol})$ or $100 \mathrm{ml}$ whisky $(43.5 \% \mathrm{vol})$ or matching volumes of control fluids. Gastric myoelectrical activity and emptying, orocecal transit and gallbladder emptying was monitored noninvasively.

Results Alcoholic beverages (beer, red wine, whisky) caused a significant slowdown of the gastric evacuation of the solid meal, the delay being the more potent, the greater was the concentration of ethanol. This inhibitory effect was not caused by interference with the gastric myoelectric activity. Alcoholic beverages produced only by fermentation (beer, red wine), at odds with the effect of their counterpartying aqueous ethanol solutions, did not elongate the orocecal transit of the solid food. Products of distillation-whisky and high proof ethanol solution-elicited a profound delay of the orocecal transit. Alcoholic beverages exerted an inhibitory effect upon the meal-stimulated gallbladder emptying, the magnitude of which increased in the order: beer $\rightarrow$ red wine $\rightarrow$ whisky.
\end{abstract}

A. Kasicka-Jonderko ( $\square) \cdot$ K. Jonderko · M. Bożek ·

M. Kamińska · P. Mgłosiek

Department of Basic Biomedical Science, School of Pharmacy,

Medical University of Silesia, Kasztanowa Street 3, 41-205

Sosnowiec, Poland

e-mail: akj@sum.edu.pl
Conclusion Alcoholic beverages exert an inhibitory effect upon the gastric emptying of a solid food and the meal-induced gallbladder emptying, whereas the effect upon the orocecal transit depends on the type of a beverage - whisky elicits a delay but beer or red wine are devoid of this effect.

Keywords Alcoholic beverages - Beer - Ethanol · Gallbladder emptying · Gastric emptying · Gastric myoelectrical activity · Orocecal transit - Whisky · Wine

\section{Introduction}

According to archaeological discoveries, alcoholic beverages accompanied the Homo sapiens ever since the deep prehistory. Nowadays their intake constitutes an inherent element of the social behaviour among western nations, as they appear to be an easy, readily accessible and efficient tool facilitating to establish and cultivate interpersonal relations.

Despite a common belief that "alcohol favours digestion" there does not exist evidence based arguments which could support such a contention. An attempt to retrieve from databases, such as Medline ${ }^{\circledR}$ and Scopus ${ }^{\circledR}$, information on the effect of alcoholic beverages on gastric emptying of nutrients, their intestinal passage, or mealstimulated gallbladder contraction brings about a scanty set of contradictory findings [1].

We designed, therefore, a study, the targets of which comprised the determination of the influence of alcoholic beverages containing different amounts of alcohol upon the postprandial gastric myoelectrical activity, gastric emptying and orocecal transit of a solid meal, as well as meal-stimulated gallbladder emptying. The following 
assumptions were made while conceiving the study protocol: (1) that customary volumes: one pint $=400 \mathrm{ml}$ of beer, one glass $=200 \mathrm{ml}$ of wine, one shot of strong alcohol customary for our geographical region $=100 \mathrm{ml}$ whisky would be taken in via the oral route, and (2) that exclusively non-invasive measurement methods would be applied.

\section{Methods}

The study was conducted on healthy volunteers aged between 21 and 32 years. Requirements for inclusion comprised: a negative result of a ${ }^{13} \mathrm{C}$-urea breath test for Helicobacter pylori infection, denial of systematic use of alcoholic beverages, and an easily visible, straight (not hook-shaped) gallbladder on ultrasonography. Exclusion conditions were: current use of any drugs, history of surgery affecting the anatomy of the digestive tract (except for an appendectomy), and pregnancy. The study was approved by the Bioethics Committee of the Medical University of Silesia. The volunteers were randomly assigned to three groups of 12 subjects each (one volunteer took part in two research blocks, another 6 agreed to participate in all three blocks), according to an intention to create three examination blocks designated: "Beer" (9F, $3 \mathrm{M}, 23.6 \pm 0.7$ years, body mass index-BMI: $20.91 \pm$ $0.80 \mathrm{~kg} \mathrm{~m}^{-2}$ ), "Wine" (7F, $5 \mathrm{M}, 24.9 \pm 1.0$ years, BMI $21.69 \pm 0.79 \mathrm{~kg} \mathrm{~m}^{-2}$ ) "Whisky" (8F, $4 \mathrm{M}, 24.3 \pm 0.8$ years, BMI $20.60 \pm 0.80 \mathrm{~kg} \mathrm{~m}^{-2}$ ).

Drinks and a solid test meal

The following alcoholic beverages were examined:

- lager beer: Pilsner Urquell (Plzeňskŷ Prazdroj a.s., Czech Republic), $4.7 \%$ vol ethanol; $185 \mathrm{~kJ}$ (44 kcal), $0.5 \mathrm{~g}$ proteins, $0 \mathrm{~g}$ fat, and $4.0 \mathrm{~g}$ carbohydrates per $100 \mathrm{~g}$;

- dry red wine: Chateau Salvanhiac appellation Saint Chinian controlée, vintage 2000 (J.C. Rouanet, France), $13.7 \%$ vol ethanol; $356 \mathrm{~kJ}$ ( $85 \mathrm{kcal}), 0.07 \mathrm{~g}$ proteins, $0 \mathrm{~g}$ fat, and $2.7 \mathrm{~g}$ carbohydrates per $100 \mathrm{~g}$;

- blended Scotch whisky: Johnnie Walker Red Label (John Walker \& Sons, Kilmarnock, UK), $43.5 \%$ vol ethanol; $992 \mathrm{~kJ}(237 \mathrm{kcal}), 0 \mathrm{~g}$ proteins, $0 \mathrm{~g}$ fat, $0 \mathrm{~g}$ carbohydrates per $100 \mathrm{~g}$;

As a solid test meal of $1485 \mathrm{~kJ}$ ( $355 \mathrm{kcal})$ was used a pancake made of two eggs, $30 \mathrm{~g}$ wheat flour and $0.1 \mathrm{~g}$ baking powder, which before serving was additionally smeared with $50 \mathrm{~g}$ of strawberry jam; it contained $15.5 \mathrm{~g}$ proteins, $16.8 \mathrm{~g}$ fat, and $43.0 \mathrm{~g}$ carbohydrates. ${ }^{13} \mathrm{C}$-octanoic acid is easily soluble in the lipids of egg yolk. Therefore, during the preparation of the pancake the two egg yolks were temporarily separated from the egg whites and thoroughly mixed with $75 \mu \mathrm{L}(68 \mathrm{mg})$ of ${ }^{13} \mathrm{C}$-octanoic acid (INC610P, Euriso-Top, France) which was instilled with the use of a precision digital micropipette. Next, the yolks were added to and stirred with the remaining ingredients with the use of an electric mixer. The dough was then transferred into a pan and fried to firm consistency with an addition of $5 \mathrm{ml}$ of sunflower oil. Accordingly, a firm bounding of ${ }^{13} \mathrm{C}$-octanoic acid with the solid meal was assured [2].

\section{Study protocol}

The subjects came to the laboratory in the morning after a 12-h overnight fast. The examination started with a 30-min record of gastric myoelectrical activity accomplished in a supine position. Then a basal probe of expiratory air was taken for ${ }^{13} \mathrm{CO}_{2}$ determination, breath $\mathrm{H}_{2}$ was measured, maximum longitudinal and transverse cross sections of the gallbladder were visualized ultrasonographically and stored on a hard disc, and a zero level of breath alcohol was verified with an alcotest.

At time " 0 " the subjects assumed a sitting position and ate within $10 \mathrm{~min}$ the solid test meal. Then they drank within up to 4 min: an alcoholic drink (beer, red wine or whisky), or an aqueous solution of an identical concentration of ethanol as contained in the beverage, or an isotonic glucose solution. Information concerning the volume, energy density and amount of alcohol contained in the drinks is assembled in Table 1 . Within every examination block the order of administration of the drinks was randomized. This was accomplished with the use of a numbered list of predefined sequences of administration of the fluids, which comprised the possible combinations of interventions and was set up before commencement of investigations. A particular sequence was allotted by the laboratory staff to subjects consecutively entering a research block.

An electrogastrogram was registered in a recumbent position until a lapse of 120 min from time " 0 "; samples of expiratory air were taken for ${ }^{13} \mathrm{CO}_{2}$ determination, breath $\mathrm{H}_{2}$ and alcohol concentrations were measured, as well as photographs of the gallbladder were repeatedly taken in accordance with a detailed time schedule outlined in Fig. 1. After completion of the electrogastrographic record, the subject took a sitting position. Breath samples for ${ }^{13} \mathrm{CO}_{2}$ were collected every fifteen $\min$ for another $4 \mathrm{~h}$. Breath alcohol was measured at 15-min intervals until a zero reading was achieved. If necessary, breath $\mathrm{H}_{2}$ concentration was monitored as long as a consistent increment $\geq 10 \mathrm{ppm}$ over the baseline occurred.

Measurement approaches

The gastric myoelectrical activity was registered with PC Polygraf HR (Synectics/Medtronics, Denmark/USA). The 
Table 1 Characteristics of fluids administered to the subjects after ingestion of a $1485 \mathrm{~kJ}$ solid test meal containing $0.068 \mathrm{~g}{ }^{13} \mathrm{C}$-octanoic acid and $10 \mathrm{~g}$ lactulose

\begin{tabular}{|c|c|c|c|c|c|c|c|c|c|c|}
\hline \multicolumn{3}{|c|}{ Control nonalcoholic solutions } & \multicolumn{4}{|c|}{ Alcoholic beverages } & \multicolumn{4}{|c|}{ Control alcoholic solutions } \\
\hline & $\begin{array}{l}\text { Energy } \\
\text { density kJ/ } \\
1 \text { (kcal/l) }\end{array}$ & $\begin{array}{l}\text { Energy } \\
\text { content } \\
\text { kJ (kcal) }\end{array}$ & & $\begin{array}{l}\text { Energy } \\
\text { density kJ/ } \\
1 \text { (kcal/l) }\end{array}$ & $\begin{array}{l}\text { Energy } \\
\text { content } \\
\text { kJ (kcal) }\end{array}$ & $\begin{array}{l}\text { Ethanol } \\
\text { content } \\
\text { (g) }\end{array}$ & & $\begin{array}{l}\text { Energy } \\
\text { density kJ/ } \\
1 \text { (kcal/l) }\end{array}$ & $\begin{array}{l}\text { Energy } \\
\text { content } \\
\text { kJ (kcal) }\end{array}$ & $\begin{array}{l}\text { Ethanol } \\
\text { content } \\
\text { (g) }\end{array}$ \\
\hline $\begin{array}{l}\text { Isotonic } \\
\text { glucose } \\
\text { solution, } \\
400 \mathrm{ml}\end{array}$ & $\begin{array}{l}837 \\
(200)\end{array}$ & $\begin{array}{l}335 \\
(80)\end{array}$ & $\begin{array}{l}\text { Beer } 4.7 \% \text { vol } \\
\text { ethanol, } \\
400 \mathrm{ml}\end{array}$ & $\begin{array}{l}1850 \\
(442)\end{array}$ & $\begin{array}{l}740 \\
(177)\end{array}$ & 14.8 & $\begin{array}{l}4.7 \% \mathrm{vol} \\
\text { ethanol } \\
\text { solution, } \\
400 \mathrm{ml}\end{array}$ & $\begin{array}{l}1070 \\
(256)\end{array}$ & $\begin{array}{l}428 \\
(102)\end{array}$ & 14.8 \\
\hline $\begin{array}{l}\text { Isotonic } \\
\text { glucose } \\
\text { solution, } \\
200 \mathrm{ml}\end{array}$ & $\begin{array}{l}837 \\
(200)\end{array}$ & $\begin{array}{l}167 \\
(40)\end{array}$ & $\begin{array}{l}\text { Red wine } \\
13.7 \% \text { vol } \\
\text { ethanol, } \\
200 \mathrm{ml}\end{array}$ & $\begin{array}{l}3560 \\
(850)\end{array}$ & $\begin{array}{l}712 \\
(170)\end{array}$ & 21.6 & $\begin{array}{l}13.7 \% \text { vol } \\
\text { ethanol } \\
\text { solution, } \\
200 \mathrm{ml}\end{array}$ & $\begin{array}{l}3119 \\
(745)\end{array}$ & $\begin{array}{l}624 \\
(149)\end{array}$ & 21.6 \\
\hline $\begin{array}{l}\text { Isotonic } \\
\text { glucose } \\
\text { solution, } \\
100 \mathrm{ml}\end{array}$ & $\begin{array}{l}837 \\
(200)\end{array}$ & $\begin{array}{l}84 \\
(20)\end{array}$ & $\begin{array}{l}\text { Whisky } \\
43.5 \% \text { vol } \\
\text { ethanol, } \\
100 \mathrm{ml}\end{array}$ & $\begin{array}{l}9916 \\
(2370)\end{array}$ & $\begin{array}{l}992 \\
(237)\end{array}$ & 34.3 & $\begin{array}{c}43.5 \% \mathrm{vol} \\
\text { ethanol } \\
\text { solution, } \\
100 \mathrm{ml}\end{array}$ & $\begin{array}{l}9916 \\
(2370)\end{array}$ & $\begin{array}{l}992 \\
(237)\end{array}$ & 34.3 \\
\hline
\end{tabular}

Fig. 1 Timetable of the measurements taken during an examination session

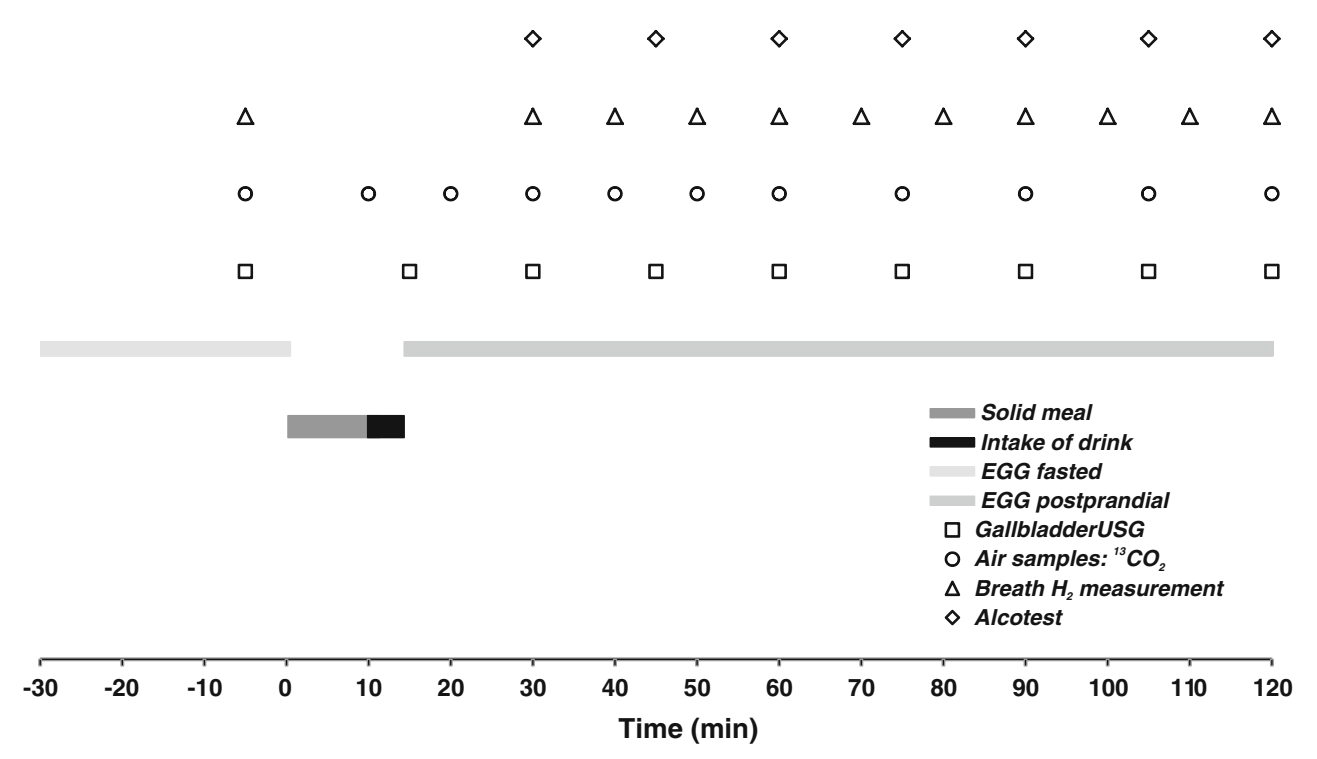

obtained electrogastrograms were analyzed as previously described in order to derive: DF-dominant frequency, $\triangle \mathrm{DP}$ - net postprandial change in dominant power, relative time shares of normogastria (2.26-3.75 cycle per minute, $\mathrm{cpm})$, bradygastria $(0.5-2.25 \mathrm{cpm})$, and tachygastria (3.76-10 cpm) during a given epoch [3].

${ }^{13} \mathrm{CO}_{2}$ content in the expiratory breath samples was determined with non-dispersive isotope-selective infrared spectrometry (IRIS apparatus, Wagner Analysen Technik Vertriebs GmbH, Germany). Subsequently the curves reflecting the cumulative ${ }^{13} \mathrm{C}$ elimination in breath air over $6 \mathrm{~h}$ were constructed as described previously [4]. With the use of a non-linear regression algorithm of Rosenbrock pattern search [5], those curves were fitted with a function $\operatorname{AUC}(t)=m\left(1-\mathrm{e}^{k t}\right)^{\beta}$, where AUC is the cumulative ${ }^{13} \mathrm{C}$ elimination as a function of time, $t$, whereas $k$ and $\beta$ are parameters of the function. The calculated $k$ and $\beta$ were used for computation of the gastric emptying parameters yielded by the ${ }^{13} \mathrm{C}$-octanoic acid breath test:

- lag phase, T_Lag ${ }_{\mathrm{BT}}=60(-1 / k) \ln \left(1-0.1^{1 / \beta}\right)$

- gastric half emptying time, $T_{1 / 2 \mathrm{BT}}=60(-1 / k) \cdot \ln (1-$ $\left.0.5^{1 / \beta}\right)$

Finally, T_Lag ${ }_{\mathrm{BT}}$ and $T_{1 / 2 \mathrm{BT}}$ were recalculated into "quasi-scintigraphic" values according to the approach proposed by Ghoos et al. [2]: T_Lag $=T_{-} L_{-} g_{B T}-$ 
$66 \mathrm{~min}$, and $T_{1 / 2}=\left(T_{1 / 2 \mathrm{BT}}-66.09\right) / 1.12$. These gastric emptying parameters were subjected to statistical analysis.

Hydrogen concentrations in expiratory air were measured with an EC-60 analyzer (Bedfont Scientific Ltd., UK). The orocecal transit time (OCTT) was defined as the time elapsing from intake of lactulose-containing meal until a sustained rise in breath hydrogen $\geq 10 \mathrm{ppm}$ over the baseline was observed [6].

The gallbladder was visualized with a Sonoline Prima apparatus (Siemens AG, Germany). Because ultrasonography may be affected by a subjective error, the operator left the examination room for the time a tested liquid was served to a subject. Gallbladder volumes were derived offline in a blind manner from an encoded series of photographs of the gallbladder according to a method of Dodds et al. [7]. The kinetics of gallbladder emptying was characterized by a maximum ejection fraction $\left(\mathrm{EF}_{\max }\right)$, time to reach it $\left(\mathrm{TEF}_{\max }\right)$, and emptying speed, V_GBE $=\mathrm{EF}_{\max } /$ $\mathrm{TEF}_{\max }$.

Ethanol in expiratory air was measured with an Alcotest 7410Plus RS (Dräger Sicherheitstechnik $\mathrm{GmbH}$, Germany). Following the manufacturer's recommendation the first measurement was taken 15 min after the alcoholic liquid was drunk. The following kinetic parameters were computed: $C_{\max }=$ peak ethanol concentration, $T_{\max }=$ time to the occurrence of $C_{\max }$, $T_{\text {elim }}=$ elimination time, i.e. the time until return of a zero reading, AUC = area under the curve of ethanol concentrations.

Power of the measurement methods and statistical analysis

Alcotest 7410 Plus RS precision amounts to $\pm 0.03 \mathrm{mg} / \mathrm{l}$ within the range from 0.00 to $0.50 \mathrm{mg} / \mathrm{l}$.

With a within-subject study protocol involving 12 paired examinations the smallest detectable difference (at $p=0.05$ level, two-tailed) amounts to:

- $10.7 \%$ and 2.19 decibel $(\mathrm{dB})$ for relative time share of normogastria and dominant power, respectively [3];

- $15.6 \mathrm{~min}$ for T_Lag and $19.7 \mathrm{~min}$ for $T_{1 / 2}$ in the case of gastric emptying of a solid meal [4];

- 26.2 min for OCTT of solids [6];

- precision of the measurement of the gallbladder volume amounts to $1.0 \pm 0.4 \mathrm{~cm}^{3}$ within the volume range from 4.0 to $30.0 \mathrm{~cm}^{3}[8]$.

Repeated measures analysis of variance (ANOVA) followed by Tukey's honest significant difference (HSD) test or Friedmann's ANOVA followed by a Wilcoxon signed rank test were applied where appropriate. The relationship between variables was checked with linear regression [5]. Statistical significance was set at $p<0.05$ level, two- tailed. Results are presented as mean $\pm \mathrm{SE}$ or as medians with interquartile ranges.

\section{Results}

Attendance

All the subjects completed the scheduled investigation sessions. The volunteers tolerated well the intake of the alcoholic beverages, as well as of the ethanol-containing counterpart solutions and non-alcoholic control fluids. The subjects were not allowed to leave the laboratory until a zero reading of the alcotest was achieved.

Kinetics of alcohol concentrations

The curves of ethanol concentration in breath air displayed in Fig. 2 indicate that a near to linear decline of ethanol concentration occurred when the drinks were taken after ingestion of a solid meal. In Table 2 data on the kinetics of breath ethanol concentration are provided.

\section{Postprandial gastric myoelectrical activity}

There was no significant effect of the type of the ingested fluid upon the dominant frequency within any of the three research blocks-Table 3. Within the blocks "Beer" and "Wine" the type of the fluid did not affect the magnitude of the $\triangle \mathrm{DP}$. Within the "Whisky" block, however, ANOVA detected a borderline statistical significance $(p=0.078)$ interaction of factors "type-of-drink" $\times$ "subperiod-ofobservation". Compared to the situation after drinking isotonic glucose, $\triangle \mathrm{DP}$ after ingestion of $100 \mathrm{ml}$ of whisky diminished from $5.70 \pm 1.35$ to $1.59 \pm 1.07 \mathrm{~dB}$ ( $p=$ 0.00012 ) during the period $16-30 \mathrm{~min}$, and from $4.57 \pm$ 1.21 to $1.79 \pm 1.16 \mathrm{~dB}(p=0.0043)$ during the next $30 \mathrm{~min}$ (Table 3.). In none of the research blocks did the type of the ingested fluid affect the relative time share of normo-, brady-, or tachygastria within the postprandial electrogastrograms (Table 4.).

Gastric emptying of the solid meal

In each research block the type of a drink exerted a statistically significant impact upon the length of T_Lag (ANOVA: $F_{2 ; 22}{ }^{1}=35.886, p<0.001$ "Beer", $F_{2 ; 22}=$ 41.936, $p<0.001$ "Wine", and $F_{2 ; 22}=38.238, p<0.001$ "Whisky"). A similar effect was found in the case of the

\footnotetext{
$\overline{{ }^{1} F_{x ; y} \text { stands }}$ for the ratio of variance with the corresponding degrees of freedom: $x$ and $y$.
} 
Fig. 2 Ethanol concentrations in expiratory air after intake in the fed state of alcoholic beverages and aqueous ethanol solution of matched concentrations (for clarity of the graph, SE bars are omitted)

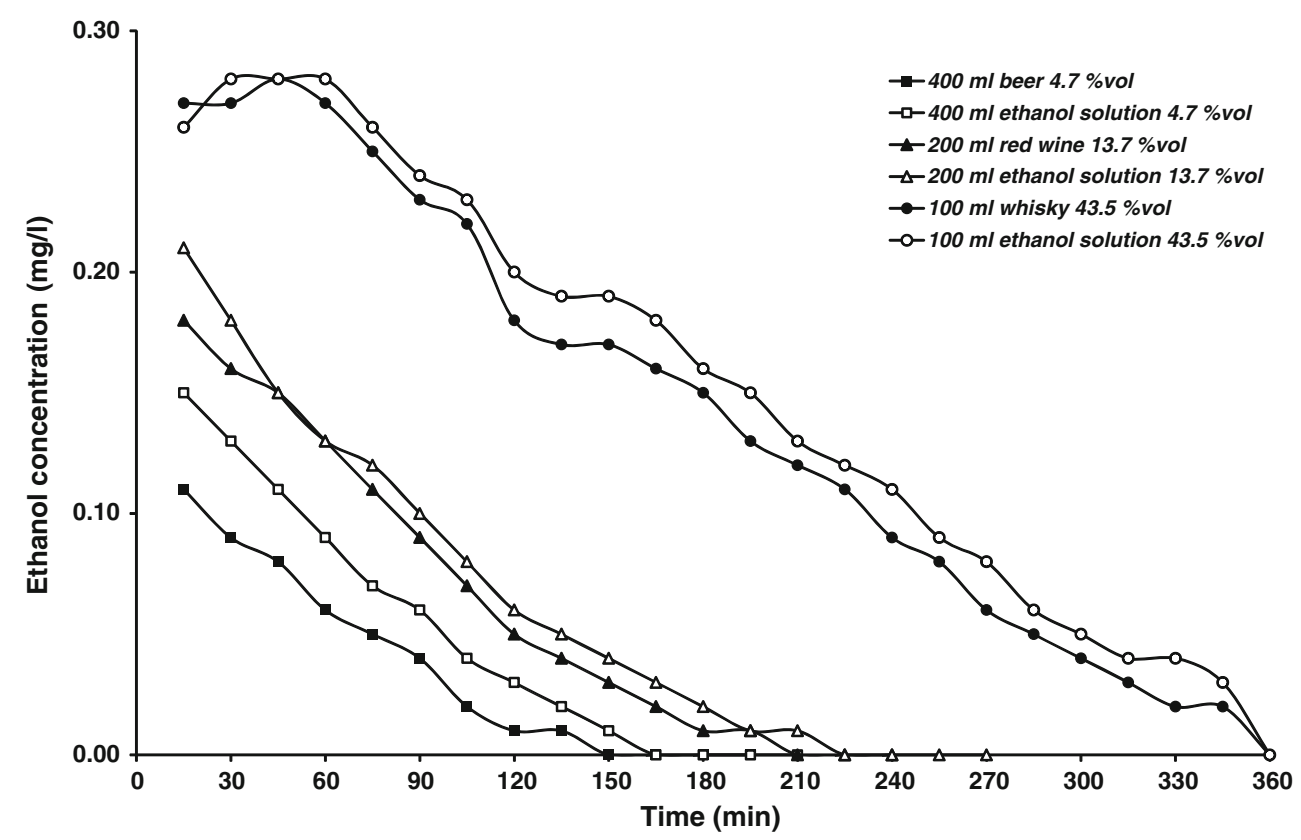

Table 2 Kinetics of ethanol concentration in expiratory air after intake of alcoholic beverages following ingestion of a solid meal

\begin{tabular}{lcccccc}
\hline & $\begin{array}{l}\text { Beer } \\
4.7 \% \text { vol }\end{array}$ & $\begin{array}{l}4.7 \% \text { vol ethanol } \\
\text { solution }\end{array}$ & $\begin{array}{l}\text { Red wine } \\
13.7 \% \text { vol }\end{array}$ & $\begin{array}{l}13.7 \% \text { vol ethanol } \\
\text { solution }\end{array}$ & $\begin{array}{l}\text { Whisky } \\
43.5 \% \text { vol }\end{array}$ & $\begin{array}{l}43.5 \% \text { vol ethanol } \\
\text { solution }\end{array}$ \\
\hline$\left.C_{\max }(\mathrm{mg} / \mathrm{l})\right)$ & $0.11 \pm 0.01^{\mathrm{a}}$ & $0.16 \pm 0.01$ & $0.19 \pm 0.01$ & $0.22 \pm 0.02$ & $0.32 \pm 0.03$ & $0.31 \pm 0.03$ \\
$T_{\max }(\min )$ & $15 \pm 1$ & $19 \pm 2$ & $20 \pm 2$ & $20 \pm 3$ & $34 \pm 6$ & $36 \pm 5$ \\
$T_{\text {elim }}(\min )$ & $121 \pm 8^{\mathrm{a}}$ & $139 \pm 8$ & $165 \pm 11^{\mathrm{a}}$ & $178 \pm 13$ & $338 \pm 22^{\mathrm{a}}$ & $356 \pm 24$ \\
$\begin{array}{l}\text { AUC }(\mathrm{mg} / \\
1 \mathrm{~min})\end{array}$ & $6.99 \pm 1.11^{\mathrm{a}}$ & $10.48 \pm 1.26$ & $15.68 \pm 2.28$ & $17.83 \pm 2.51$ & $50.41 \pm 5.76$ & $54.79 \pm 7.13$ \\
\hline
\end{tabular}

$C_{\max }$ maximum concentration, $T_{\max }$ time to $C_{\max }$ occurrence, $T_{\text {elim }}$ time to achieve a zero reading on the alcotest, $A U C$ area under the curve of breath ethanol concentration

a Statistically significant difference between an alcoholic beverage and an aqueous ethanol solution of a matching concentration

$T_{1 / 2}: F_{2 ; 22}=13.111, p<0.001, F_{2 ; 22}=18.950, p<0.001$, and $F_{2 ; 22}=16.503, p<0.001$ within the blocks "Beer", "Wine", and "Whisky", respectively. The results of post hoc comparison among the pertinent averages are assembled in Table 5. The slowing effect upon the gastric emptying of solids increased following the order: low $\rightarrow$ moderate $\rightarrow$ high alcohol proof. No differences were found in the solid phase gastric emptying after drinking the examined alcoholic beverages and after intake of aqueous solutions of a matched ethanol concentration.

Orocecal transit of the solid meal

In the block "Beer" the impact of the type of beverage upon OCTT approached the threshold of statistical significance $\left(F_{2 ; 22}=2.814, p=0.082\right)$. The OCTT after drinking beer was slightly and statistically not significantly shorter than after drinking the same volume of $5 \%$ glucose. On the contrary, ingestion of the low proof aqueous ethanol solution prolonged the OCTT of the solid food (Table 6).
Within the research block "Wine" a statistically significant effect of the type of the drink upon the length of the OCTT was disclosed $\left(F_{2 ; 22}=13.270, p<0.001\right)$. It was found that, when referred to the intake of isotonic glucose, red wine did not prolong the OCTT, whereas $13.7 \%$ vol aqueous ethanol solution brought about a marked increase in the OCTT (Table 6).

A significant effect of the ingested liquid upon the OCTT of solids was also detected in the block "Whisky": $F_{2 ; 22}=25.759, p<0.001$. In this case, however, both high proof beverages considerably prolonged the OCTT, which appeared to be $>100$ min longer than in the control situation after drinking $100 \mathrm{ml}$ of $5 \%$ glucose (Table 6).

Meal-induced gallbladder emptying

A visual inspection of the curves depicted in Fig. 3 implies a marked inhibitory influence of alcoholic beverages or aqueous ethanol solutions on the postprandial gallbladder emptying. 


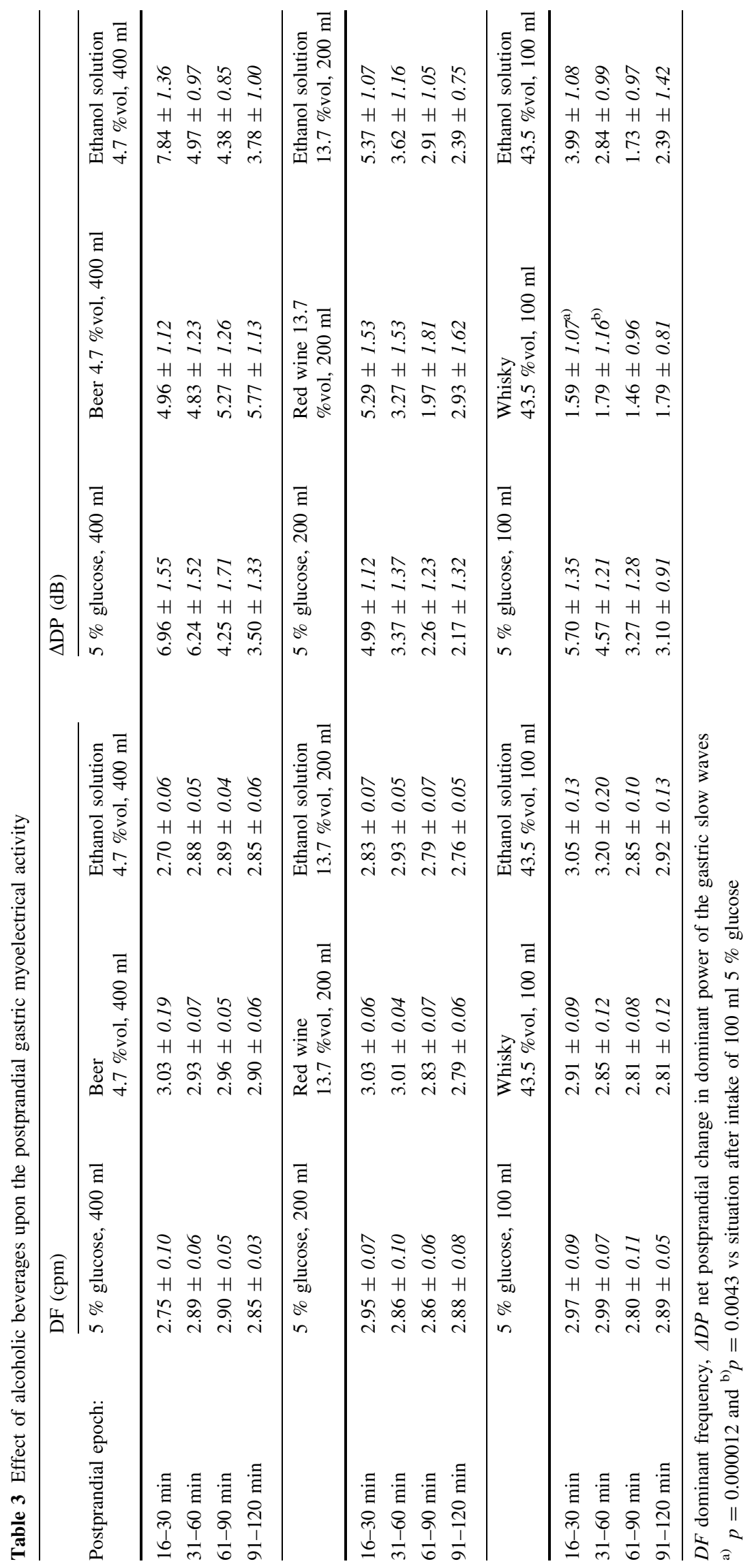




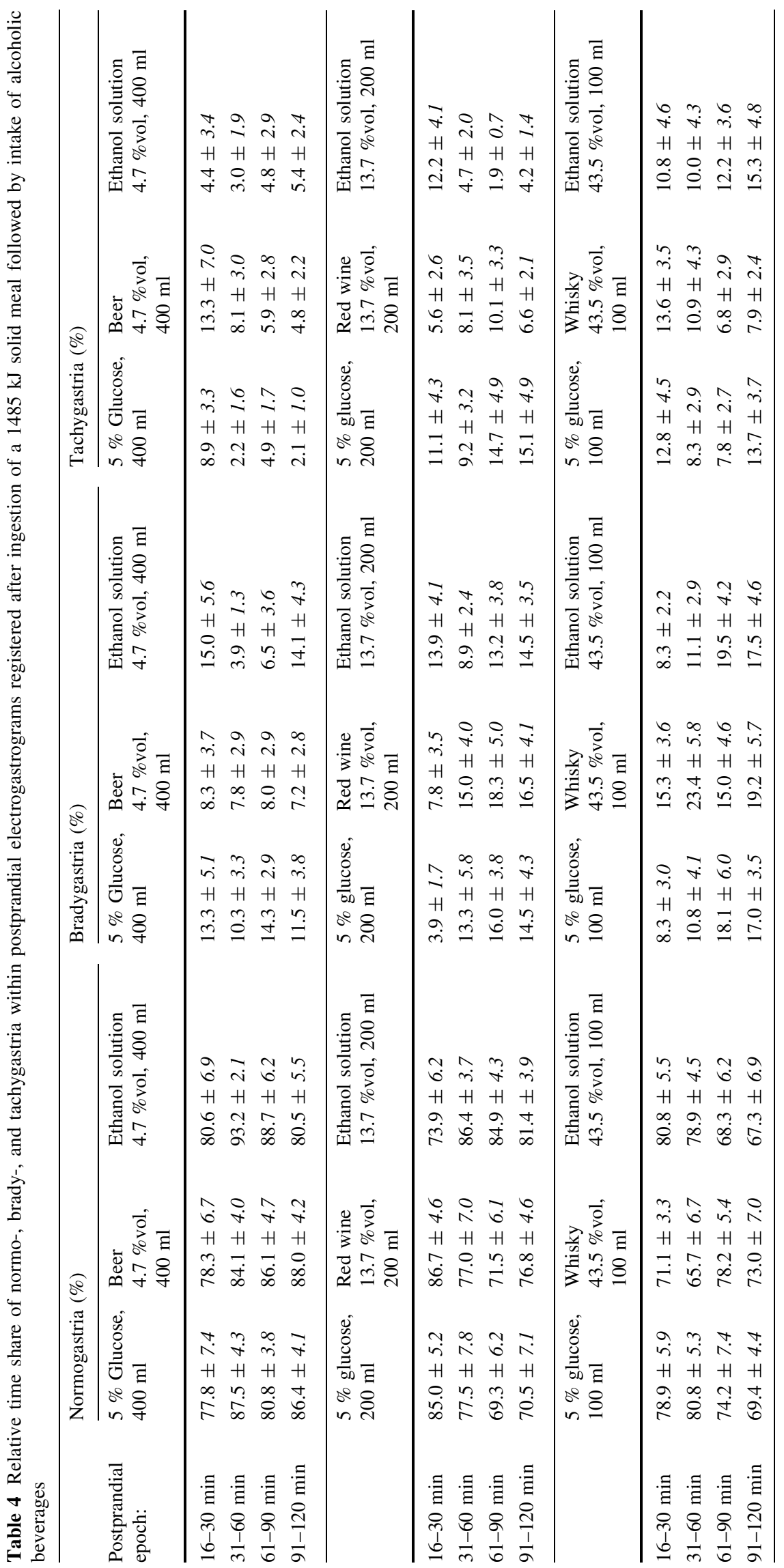


Table 5 Effect of alcoholic beverages upon the gastric emptying of a solid meal

\begin{tabular}{|c|c|c|c|c|c|c|c|c|}
\hline $\begin{array}{l}\text { Control liquid I } \\
\text { (nonalcoholic) }\end{array}$ & $\begin{array}{l}\text { T_Lag } \\
(\min )\end{array}$ & $\begin{array}{l}T_{1 / 2} \\
(\mathrm{~min})\end{array}$ & Alcoholic beverages & $\begin{array}{l}\text { T_Lag } \\
(\min )\end{array}$ & $T_{1 / 2}(\min )$ & $\begin{array}{l}\text { Control liquid II } \\
\text { (alcoholic) }\end{array}$ & $\begin{array}{l}\text { T_Lag } \\
(\min )\end{array}$ & $T_{1 / 2}(\min )$ \\
\hline $\begin{array}{l}\text { Isotonic glucose } \\
\text { solution, } 400 \mathrm{ml}\end{array}$ & $42 \pm 4$ & $155 \pm 7$ & $\begin{array}{l}\text { Beer } 4.7 \% \text { vol, } \\
\quad 400 \mathrm{ml}\end{array}$ & $84 \pm 7^{a}$ & $\underset{b}{206} \pm 11$ & $4.7 \% \mathrm{vol}, 400 \mathrm{ml}$ & $73 \pm 6^{c}$ & $197 \pm 9^{d}$ \\
\hline $\begin{array}{l}\text { Isotonic glucose } \\
\text { solution, } 200 \mathrm{ml}\end{array}$ & $30 \pm 3$ & $144 \pm 6$ & $\begin{array}{l}\text { Red wine } 13.7 \% \text { vol, } \\
200 \mathrm{ml}\end{array}$ & $79 \pm 7^{e}$ & $\underset{f}{209} \pm 11$ & $13.7 \% \mathrm{vol}, 200 \mathrm{ml}$ & $76 \pm 4^{g}$ & $207 \pm 9^{h}$ \\
\hline $\begin{array}{l}\text { Isotonic glucose } \\
\text { solution, } 100 \mathrm{ml}\end{array}$ & $26 \pm 4$ & $144 \pm 8$ & $\begin{array}{l}\text { Whisky } 43.5 \% \text { vol, } \\
100 \mathrm{ml}\end{array}$ & $86 \pm 5^{i}$ & $\underset{j}{248} \pm 16$ & $43.5 \% \mathrm{vol}, 100 \mathrm{ml}$ & $79 \pm 7^{k}$ & $242 \pm 16^{l}$ \\
\hline
\end{tabular}

$T \_L a g$ lag phase, $T_{1 / 2}$ gastric half emptying time

Within the particular examination blocks the following differences were found to be statistically significant

Block "Beer": ${ }^{\mathrm{a}} p=0.000136$ and ${ }^{\mathrm{c}} p=0.000146$ in comparison to $\mathrm{T}_{-} \mathrm{Lag}$, as well as ${ }^{\mathrm{b}} p=0.000368$ and ${ }^{\mathrm{d}} p=0.00188$ in comparison to $T_{1 / 2}$ of a solid meal after intake of $400 \mathrm{ml}$ of $5 \%$ glucose solution

Block "Wine": ${ }^{\mathrm{e}} p=0.000136$ and ${ }^{\mathrm{g}} p=0.000146$ in comparison to T_Lag, as well as ${ }^{\mathrm{f}} p=0.000180$ and ${ }^{\mathrm{h}} p=0.000207$ in comparison to $T_{1 / 2}$ of a solid meal after intake of $200 \mathrm{ml}$ of $5 \%$ glucose solution

Block "Whisky": ${ }^{\mathrm{i}} p=0.000136$ and ${ }^{\mathrm{k}} p=0.000136$ in comparison to T_Lag, as well as ${ }^{\mathrm{j}} p=0.000232$ and ${ }^{1} p=0.000350$ in comparison to $T_{1 / 2}$ of a solid meal after intake of $100 \mathrm{ml}$ of $5 \%$ glucose solution

Table 6 Effect of alcoholic beverages and control solutions on the orocecal transit time (OCTT: min) of a solid meal

\begin{tabular}{|c|c|c|c|c|c|}
\hline \multicolumn{2}{|l|}{ Control liquid I (nonalcoholic) } & \multicolumn{2}{|l|}{ Alcoholic beverages } & \multicolumn{2}{|c|}{ Control liquid II (alcoholic) } \\
\hline Isotonic glucose solution, $400 \mathrm{ml}$ & $215 \pm 19$ & Beer $4.7 \%$ vol, $400 \mathrm{ml}$ & $203 \pm 12$ & $4.7 \% \mathrm{vol}, 400 \mathrm{ml}$ & $248 \pm 18^{\mathrm{a}}$ \\
\hline Isotonic glucose solution, $200 \mathrm{ml}$ & $205 \pm 14$ & Red wine $13.7 \%$ vol, $200 \mathrm{ml}$ & $189 \pm 17$ & $13.7 \% \mathrm{vol}, 200 \mathrm{ml}$ & $266 \pm 11^{\mathrm{b}, \mathrm{c}}$ \\
\hline Isotonic glucose solution, $100 \mathrm{ml}$ & $214 \pm 20$ & Whisky $43.5 \%$ vol, $100 \mathrm{ml}$ & $319 \pm 17^{d}$ & $43.5 \%$ vol, $100 \mathrm{ml}$ & $315 \pm 11^{\mathrm{e}}$ \\
\hline
\end{tabular}

Within the particular examination blocks the following differences were found to be statistically significant

Block "Beer": ${ }^{\mathrm{a}} p=0.00199$ in comparison to OCTT of a solid meal after intake of $400 \mathrm{ml}$ beer

Block "Wine": ${ }^{\mathrm{b}} p=0.00505$ in comparison to OCTT of a solid meal after intake of $200 \mathrm{ml}$ of $5 \%$ glucose solution and ${ }^{\mathrm{c}} p=0.000735$ in comparison to OCTT of a solid meal after intake of red wine

Block "Whisky": ${ }^{\mathrm{d}} p=0.000169$ and ${ }^{\mathrm{e}} p=0.000190$ in comparison to OCTT of a solid meal after intake of $100 \mathrm{ml}$ of $5 \%$ glucose solution

A statistically significant effect of the type of drink on the $\mathrm{EF}_{\max }$ in the blocks "Wine" $\left(F_{2 ; 22}=3.620\right.$, $p=0.044)$ and "Whisky" $\left(F_{2 ; 22}=10.589, p=0.00060\right)$ was detected, whereas in the block "Beer" this effect was statistically not significant. $\mathrm{EF}_{\text {max }}$ after drinking red wine, whisky, and high-proof ethanol solution was statistically significantly lower than on the day of intake of isotonic glucose at corresponding volumes (Table 7).

Friedman ANOVA excluded a significant impact of the type of the ingested fluid upon the $T_{\max }$. On the other hand, within every of the three blocks, the type of beverage significantly influenced the rate of emptying of the gallbladder: "Beer" $-\chi^{2}=9.500, p=0.0087$, "Wine"- $\chi^{2}=6.000$, $p=0.049$, "Whisky"- $\chi^{2}=10.500, p=0.0052$. A significantly lower V_GBE characterized gallbladder emptying after drinking beer, red wine, whisky, and after ingestion of $100 \mathrm{ml}$ of $43.5 \%$ vol ethanol solution (Table 7).

\section{Analysis of relationships}

Several statistically significant correlations were found which are assembled in Table 8.

\section{Discussion}

Limitations of the study and measures undertaken to overcome them

Alcoholic beverages and aqueous ethanol solutions do have characteristic organoleptic features, such as taste, smell, and at times also colour which impede performance of a study according to a fully blinded protocol, if the fluids have to be taken orally. This was the case of our project, the principle assumption of which was the application of solely non-invasive procedures (e.g., an intragastric instillation of alcoholic beverages definitely would stand in contradiction with the real life situation). It should be pointed out, however, that the majority of outcome measures: the breath ethanol concentration, parameters describing the gastric myoelectrical activity, quantitative results ${ }^{13} \mathrm{CO}_{2}$ and $\mathrm{H}_{2}$ breath tests characterizing, respectively, the gastric emptying speed and OCTT are derived with the use of dedicated software and thus are objective, and operator-independent. On the other hand, prone to operator-dependent bias might be serial ultrasonographic 
Fig. 3 Effect of alcoholic beverages and control solutions upon meal-stimulated gallbladder emptying (for clarity of the graph, SE bars are omitted)

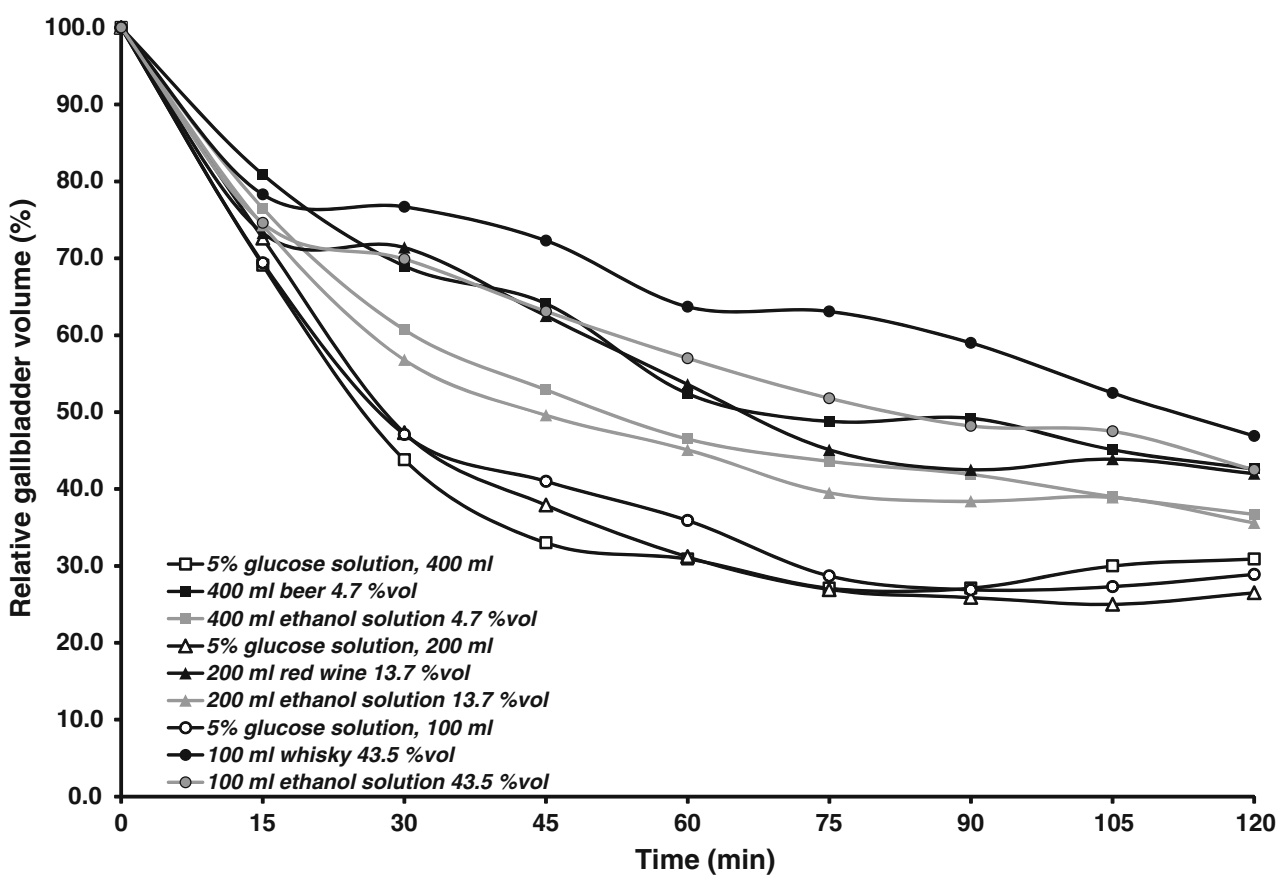

visualisation of the gallbladder, which is required to collect data for construction of gallbladder emptying curves. We decided, therefore, to blind the ultrasonographist as concerns the fluid ingested by the subjects and the proper volume measurements were performed off-line from an encoded series of photographs.

A problem which has to be confronted and solved at the moment of designing a protocol of a study aimed at examination of alcohol effects upon the digestive tract is the choice of proper control solutions. Taking into account the low molecular weight of ethyl alcohol, while computing theoretical osmolality, one would obtain rather shocking values, such as 845,2711 and $13186 \mathrm{mmol} / \mathrm{kg}$ in the case of $4.7,13.7$, and $43.5 \%$ vol, respectively. This reasoning is, however, burdened with an essential error, because due to a very small dimension of the ethanol molecule $(2.6 \AA)$ this compound easily passes through biological membranes, such as the mucosa of the stomach or the small intestine, behaving like a solution of a zero osmolality coefficient. Therefore, not only there is no need to consider the theoretical osmolality of ethanol solutions, but on the contrary - such an attempt would bring up quite an absurd result. Just to say that a $\mathrm{NaCl}$ solution at a concentration of $27 \mathrm{~g} / \mathrm{l} \mathrm{H}_{2} \mathrm{O}$ reaches osmolality amounting to "barely" $827 \mathrm{mmol} / \mathrm{kg}$. Recent research indicates that ingestion of such a hyperosmotic $\mathrm{NaCl}$ solution elicits a profound disruption of the gastric myoelectrical activity [9].

Another important feature of ethyl alcohol to be considered is the fact that it is a high-energy compound, providing $21.7 \mathrm{~kJ} / \mathrm{g}(7.1 \mathrm{kcal} / \mathrm{g})$. So, for example, if one tried to compose a fluid isoenergetic with red wine applied in this study, a glucose concentration of $186 \mathrm{~g} / 1 \mathrm{H}_{2} \mathrm{O}$ would have to be used. Such a solution would be definitely hyperosmotic (1034 mmol/kg), and previous research demonstrated that just a less hyperosmotic glucose solution $(150 \mathrm{~g} / \mathrm{l}$ $\mathrm{H}_{2} \mathrm{O}$, osmolality $836 \mathrm{mmol} / \mathrm{kg}$ ) disrupts the gastric myoelectrical activity, bringing about a characteristic increase in tachygastria share within the electrogastrogram [9].

According to our experience not even distilled water would be recommendable as a control liquid in a study on the effects of alcohol on the digestive system, as was suggested by other authors [10]. Recent research indicates that being a zero osmotic fluid, distilled water, does not exert a neutral effect upon the physiology of the gastrointestinal tract. It was found that intake of distilled water results in a modest disruption of the gastric myoelectrical activity [9]. In healthy subjects an optimum record of gastric myoelectric activity will be achieved with ingestion of isotonic glucose solution because stimulation of chemoreceptors sensitive to glucose elicits a positive chronotropic effect and stabilization of the gastric pacemaker activity [9].

With all the above remarks in mind, we decided to apply in this study an isotonic glucose solution as the reference nonalcoholic fluid as it would be expected to warrant an optimum referential pattern of gastric myoelectrical activity in terms of the relative time share of normogastria, and the postprandial increase in the dominant frequency and power [9].

Alcoholic beverages and postprandial gastric myoelectrical activity

There were few attempts formerly addressing the effect of alcoholic fluids upon the postprandial gastric myoelectrical activity. 


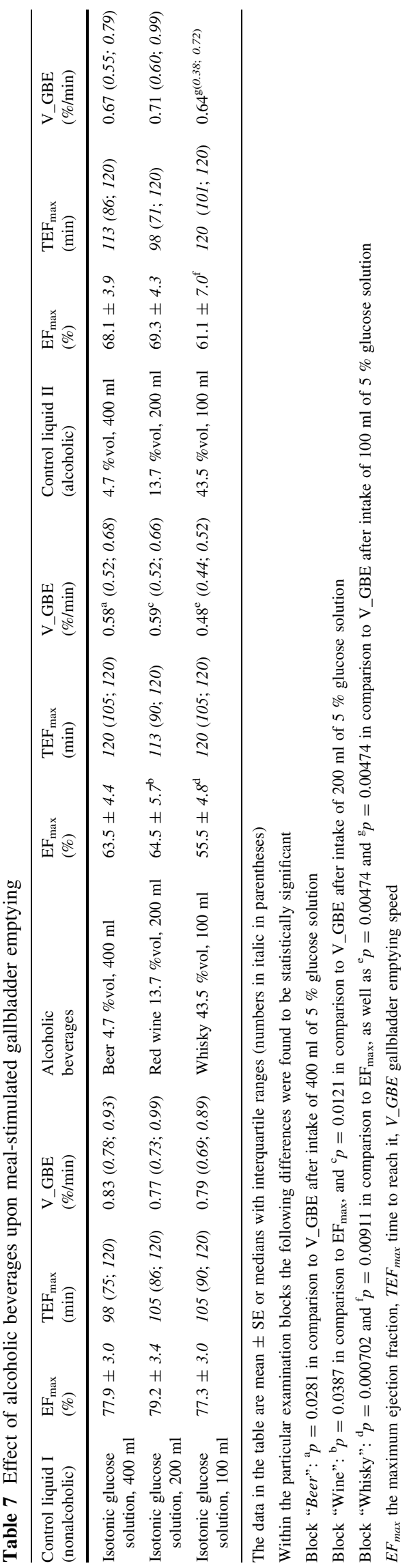

Levanon et al. [11] reported that intake of $12.5 \% \mathrm{vol}$ Australian white wine 30 min prior to ingestion of a mixed $1987 \mathrm{~kJ}$ (475 kcal) meal resulted in a decreased postprandial $\Delta \mathrm{DP}$. It should be noted that isoenergetic to the wine fluid (juice) would have osmolality of about $1000 \mathrm{mmol} / \mathrm{kg}$, which would account for a greater $\Delta \mathrm{DP}$ in the control experiment [9].

Turkish researchers [12] found that $40 \%$ vol ethanol contained in juice did not affect the gastric myoelectrical activity after ingestion of a mixed meal test of $2092 \mathrm{~kJ}$ (500 kcal).

The results obtained in our study add, thus, new information: (1) ingestion of alcoholic beverages within a large range of ethanol concentrations does not affect the rhythmicity of the postprandial gastric myoelectrical activity, and (2) with the exception of whisky, none of the beverages or control alcoholic solutions was capable of suppressing the meal-induced increase in the dominant power of the gastric slow waves. The protocol of our study did not permit us to explain why just whisky, and not the $43.5 \%$ vol ethanol solution, exerted the effect mentioned. One would think, however, of an inhibitory role of compounds which are contained in this beverage as a result of the technological process of its production [13].

\section{Alcoholic beverages and gastric emptying of solids}

Prior investigation addressed solely the effect of alcoholic beverages on the gastric emptying of liquid caloric meals $[14,15]$, whereas recently the choice of the ultrasonographic method of monitoring the antral volume precluded distinguishing between the gastric emptying of the liquid and the solid phase of a meal after intake of alcoholic beverages [16].

The problem mentioned was successfully overcome in our study, because thanks to selective labeling with ${ }^{13} \mathrm{C}$ octanoic acid, we were able to prove that beer, red wine, whisky, as well as aqueous ethanol solutions of matching proofs, exert an explicit delaying effect on the gastric emptying of the solid food. Our findings are supported in part by a recent report by Heinrich et al. [17], who used labelling with ${ }^{13} \mathrm{C}$-sodium octanoate, and observed a slowing of gastric evacuation of the solid phase exerted by $20 \mathrm{ml}$ white cherry vodka.

Our study provides important new findings. Firstly, that the slowing of gastric emptying of solids elicited by alcoholic beverages was unrelated to the gastric myoelectrical activity. Secondly, that intake of an alcoholic beverage and a concentration-matched aqueous ethanol solution results in similar elongations of T_Lag and $T_{1 / 2}$, which implies the role of ethanol in this delaying effect. Indeed, the net slowing of gastric emptying, taken as a difference in T_Lag and $T_{1 / 2}$ length after ingestion of alcoholic fluids and after intake of isotonic glucose, correlated closely with ethanol 
Table 8 Interplay among the changes of gastric myoelectrical activity, transport function of the digestive tract, and gallbladder emptying elicited by intake of alcoholic beverages after ingestion of a solid meal

\begin{tabular}{|c|c|c|c|c|c|c|c|c|}
\hline & Eta\% & $C_{\max }$ & AUC & $\Delta \_$Normo & $\Delta \_\Delta \mathrm{DP}$ & $\Delta \_T \_L a g$ & $\Delta \_T_{1 / 2}$ & $\Delta \_$OCTT \\
\hline$\Delta \_$Normo & ns & $\mathrm{ns}$ & ns & & & & & \\
\hline$\Delta \_\Delta \mathrm{DP}$ & ns & ns & ns & & & & & \\
\hline$\Delta \_T \_L a g$ & 0.37 & 0.24 & 0.29 & ns & $\mathrm{ns}$ & & & \\
\hline$\Delta \_T_{1 / 2}$ & 0.44 & 0.28 & 0.35 & ns & ns & & & \\
\hline$\Delta \_\mathrm{OCTT}$ & 0.52 & 0.54 & 0.58 & ns & -0.26 & 0.27 & 0.24 & \\
\hline$\Delta \_\mathrm{EF}_{\max }$ & ns & -0.24 & -0.35 & ns & ns & ns & ns & -0.24 \\
\hline$\Delta_{-} \mathrm{TEF}_{\max }$ & ns & $\mathrm{ns}$ & ns & ns & ns & ns & ns & ns \\
\hline$\Delta \_$V_GBE & -0.25 & ns & -0.24 & ns & ns & ns & ns & $\mathrm{ns}$ \\
\hline
\end{tabular}

The analysis was performed on a series of net differences (marked with a prefix $\Delta_{-}$) between the value of a given parameter after intake of an alcoholic beverage or aqueous ethanol solution of matching concentration and its value established after ingestion of a corresponding volume of isotonic glucose. The numbers given in the table are statistically significant coefficients of linear regression $(N=72)$

$n s$ no significant correlation was found, Eta\% ethanol concentration within an alcoholic beverage or aqueous solution, $C_{\max }$ maximum concentration, $A U C$ area under the curve of ethanol concentration in expiratory air, Normo relative time share of normogastria, $\triangle D P$ net postprandial change in dominant power, $T_{-} L a g$ lag phase, $T_{1 / 2}$ gastric half emptying time of a solid meal, OCTT orocecal transit time of a solid meal, $E F_{\max }$ gallbladder maximum ejection fraction, $T E F_{\max }$ time of its occurrence, $V \_G B E$ gallbladder emptying speed

concentration in them. A significant correlation was also found between the elongation of T_Lag or $T_{1 / 2}$ and the $C_{\max }$ and AUC which are parameters reflecting the body ethanol concentration (cf. Table 8.). Formerly Linda Knight et al. [18] observed in dogs a stronger inhibitory effect on gastric emptying when ethanol was ingested than when its solution was administered intravenously.

\section{Alcoholic beverages and orocecal transit of a solid meal}

The effect of alcoholic beverages upon the OCTT of solids in humans was not examined before. In comparison to the control situation with isotonic glucose, we found that each of the three aqueous solutions of ethanol (4.7, 13.7, and $43.5 \%$ vol) and whisky elicited a significant retarding effect on the OCTT. It should be pointed out that with the measurement by means of the hydrogen breath test, the resulting OCTT length consists of the esophageal transit (short enough to be omitted), gastric evacuation, and the passage of the lactulose-containing meal along the small intestine until its head reaches the caecum. One should, therefore, attempt to distinguish whether the retardation of OCTT could result from a luminal effect of ethanol upon the intestine, or was just secondary to the delay in gastric emptying discussed in the former chapter. The correlation analysis (cf. Table 8) did not provide adjudication in this respect. It showed, on the one hand, that the net elongation of OCTT was bound with by a significant correlation with ethanol concentration within the drinks, and the parameters reflecting the body ethanol concentration ( $C_{\max }$ and AUC). On the other hand, the net OCTT changes correlated significantly with the alcohol-elicited increases in the gastric emptying parameters: the T_Lag and $T_{1 / 2}$.
Interestingly, beer did not prolong orocecal transit, and red wine even slightly shortened the OCTT of the solid food. Nevertheless, if beer or wine did not prolong the OCTT measured with the hydrogen breath test, while simultaneously their delaying effect on the gastric emptying of solids was demonstrated, an implication arises that in both instances a stimulating effect of some compounds present in those two alcoholic beverages upon the intestinal motility might be elicited. So far two such compounds exerting in vitro a motility stimulating effect-aperidine and hordatine $\mathrm{A}$-were isolated from beer [19].

Alcoholic beverages and meal-stimulated gallbladder emptying

Epidemiological studies indicate that regular consumption of moderate amounts of alcohol reduces the risk of gallbladder stones [20]. Is it therefore possible that alcoholic beverages could somehow improve gallbladder motility and prevent bile stasis?

The only work on the impact of acute exposure to an alcoholic beverage on meal-stimulated gallbladder emptying was published by Patricia Modaine et al. [21] who demonstrated ultrasonographically a significant inhibitory effect of rum $(50 \mathrm{ml} 50 \% \mathrm{vol})$ on the postprandial gallbladder emptying evoked by a liquid caloric meal.

We demonstrated for the first time that ingestion of alcoholic beverages elicits a suppressive effect on gallbladder emptying evoked by a solid meal. Depending on the pattern of observed changes of the kinetic parameters, gallbladder emptying may appear to be inhibited, delayed, or inhibited and delayed. In this study a decreased $\mathrm{EF}_{\max }$ accompanied by an unchanged $\mathrm{TEF}_{\max }$ was observed, 
which implies that alcoholic beverages elicited a true inhibition of the meal-stimulated gallbladder emptying. The $\mathrm{EF}_{\max }$ diminished already after ingestion of beer, yet statistically significant decreases in $\mathrm{EF}_{\max }$ relative to the control situation with isotonic glucose were observed after intake of red wine, whisky, and $43.5 \%$ vol ethanol solution. In interesting pattern of links was revealed by the correlation analysis (cf. Table 8) - the $\mathrm{EF}_{\max }$ decreased the more, the higher were $C_{\max }$ and AUC, and the longer was the OCTT of the solid meal. The latter relationship would indicate the importance of the contact time of food containing ethanol with the intestinal wall for the intensification of the inhibitory effect of alcohol on the gallbladder emptying.

The meal-stimulated gallbladder emptying is quite a complex physiological process, but a leading role in it involves the release of cholecystokinin (CCK) from I-cells dispersed within the mucosal of the duodenum and jejunum. The impact of CCK upon the discharge of bile is dichotomic in nature, since CCK is responsible for the contraction of the gallbladder, and at the same time it facilitates the outflow of bile through a dilatatory effect on the sphincter of Oddi [22]. Hence, from the point of view of hydrodynamics, a decreased $\mathrm{EF}_{\max }$ may result from an increased resistance to flow of insufficiently relaxed sphincter of the hepatopancreatic ampulla. Unfortunately, at present this hypothesis cannot be verified because the published results on the effect of ethanol upon the human sphincter of Oddi appear to be largely inconsistent [23-26].

\section{Closing remarks and conclusion}

The examinations were accomplished with particular brands of beer, red wine, and whisky. No great oenologic knowledge is required to understand that depending on a good or bad vintage, a particular appellation of wine may strongly differ with regard to the bouquet and taste, which result from an interplay of dozens if not hundreds of compounds contained in it. A similar opinion would be expressed by connoisseurs of beer or whisky. Therefore, we are aware that the results obtained and discussed in this paper cannot automatically be extrapolated to every beer, red wine or whisky.

Nevertheless the results obtained permit us to conclude that alcoholic beverages exert an inhibitory effect upon the gastric emptying of a solid food and the meal-induced gallbladder emptying, whereas the effect upon the orocecal transit depends on the type of a beverage-whisky elicits a delay but beer or red wine are devoid of this effect.

Acknowledgments Preliminary conceptual work was supported by a grant from the Medical University of Silesia (contract NN-1-088/ $01)$. The proper research was financed from a research grant
3P05B16722 obtained from the State Committee For Scientific Research (currently: The Ministry of Science and Higher Education) of the Republic of Poland-contract \# 0450/P05/2002/22. Lactulose sirup was a gift from Molteni Farmaceutici Polska sp. z o.o. The alcoholic beverages were funded by AKJ.

Conflict of interest All authors declare: no authors had financial support for the submitted work; no financial relationships with any organisations that might have an interest in the submitted work in the previous 3 years; no other relationships or activities that could appear to have influenced the submitted work. The authors confirm their independence from the funders.

Ethical standard The study was approved by the Bioethics Committee of the Medical University of Silesia (decision \# NN-013-39/ 02).

Open Access This article is distributed under the terms of the Creative Commons Attribution Noncommercial License which permits any noncommercial use, distribution, and reproduction in any medium, provided the original author(s) and the source are credited.

\section{References}

1. Kasicka-Jonderko A. Alcohol and the digestive system-should it always be blamed? Prz Gastroenterol. 2012;7:264-75.

2. Ghoos YF, Maes BD, Geypens BJ, Mys G, Hiele MI, Rutgeerts PJ, et al. Measurement of gastric emptying rate of solids by means of a carbon-labeled octanoic acid breath test. Gastroenterology. 1993;104:1640-7.

3. Jonderko K, Kasicka-Jonderko A, Krusiec-Świdergoł B, Dzielicki M, Strój L, Doliński M, et al. How reproducible is cutaneous electrogastrography? An in-depth evidence-based study. Neurogastroenterol Motil. 2005;17:800-9.

4. Kasicka-Jonderko A, Kamińska M, Jonderko K, Setera O, Błońska-Fajfrowska B. Short- and medium-term reproducibility of gastric emptying of a solid meal determined with the use of a low dose of ${ }^{13} \mathrm{C}$-octanoic acid and isotope-selective nondispersive infrared spectrometry. World J Gastroenterol. 2006;12:1243-8.

5. StatSoft, Inc. Electronic statistics textbook. Tulsa, OK: StatSoft; 2012. http://www.statsoft.com/textbook/stathome.html.

6. Matusiński M, Jonderko K, Kasicka-Jonderko A, Błońska-Fajfrowska B. Reproducibility of the oro-caecal transit time (OCTT) of a solid meal. J Gastroenterol Hepatol. 2006;21(Suppl. 6):A498.

7. Dodds WJ, Groh WJ, Darweesh RM, Lawson TL, Kishk SM, Kern MK. Sonographic measurement of gallbladder volume. Am J Roentgenol. 1985;145:1009-11.

8. Jonderko K, Buéno L. Validation in vivo of an ultrasonographic method of measuring gallbladder volume. Ultrason Pol. 1994;4:53-60.

9. Syrkiewicz-Trepiak D, Jonderko K, Kasicka-Jonderko A. Effect of osmolality of caloric and acaloric liquids on gastric myoelectrical activity in humans. Med Sci Monit. 2010;16:CR252-9.

10. Chari ST, Teyssen S, Singer MV. What controls should be used in studies of acute effects of alcohol and alcoholic beverages on the stomach and the pancreas? Scand J Gastroenterol. 1993;28:289-95.

11. Levanon D, Goss B, Chen JD. Inhibitory effect of white wine on gastric myoelectrical activity and the role of vagal tone. Dig Dis Sci. 2002;47:2500-5.

12. Celebi Kobak A, Bor S. The acute effect of oral ethanol intake on gastric myoelectrical activity in healthy volunteers. Turk J Gastroenterol. 2007;18:221-4. 
13. Iino T, Nakahara K, Miki W, Kiso Y, Ogawa Y, Kato S, et al. Less damaging effect of whisky in rat stomachs in comparison with pure ethanol. Role of ellagic acid, the nonalcholic component. Digestion. 2001;64:214-21.

14. Barboriak JJ, Meade RC. Effect of alcohol on gastric emptying in man. Am J Clin Nutr. 1970;23:1151-3.

15. Mushambi MC, Bailey SM, Trotter TN, Chadd GD, Rowbotham DJ. Effect of alcohol on gastric emptying in volunteers. Br J Anaesth. 1993;71:674-6.

16. Franke A, Nakchbandi IA, Schneider A, Harder H, Singer MV. The effect of ethanol and alcoholic beverages on gastric emptying of solid meals in humans. Alcohol Alcohol. 2005;40:187-93.

17. Heinrich H, Goetze O, Menne D, Iten PX, Fruehauf H, Vavricka $\mathrm{SR}$, et al. Effect on gastric function and symptoms of drinking wine, black tea, or schnapps with a Swiss cheese fondue: randomised controlled crossover trial. Br Med J. 2010;341:c6731. doi:10.1136/bmj.c6731.

18. Knight LC, Maurer AH, Wikander R, Krevsky B, Malmud LS, Fisher RS. Effect of ethyl alcohol on motor function in canine stomach. Am J Physiol. 1992;262:G223-30.

19. Yamaji N, Yokoo Y, Iwashita T, Nemoto A, Koike M, Suwa Y, et al. Structural determination of two active compounds that bind to the muscarinic M3 receptor in beer. Alcohol Clin Exp Res. 2007;31(Suppl. 1):S9-14.
20. Leitzmann MF, Giovannucci EL, Stampfer MJ, Spiegelman D, Colditz GA, Willett WC, et al. Prospective study of alcohol consumption patterns in relation to symptomatic gallstone disease in men. Alcohol Clin Exp Res. 1999;23:835-41.

21. Modaine P, Davion T, Capron D, Capron JP. Étude échographique de la motricité vésiculaire du sujet sain. Reproducibilité de la méthode et effet de l'alcool. Gastroenterol Clin Biol. 1993;17: 839-44.

22. Portincasa P, Di Ciaula A, Wang HH, Palasciano G, van Erpecum $\mathrm{KJ}$, Moschetta A, et al. Coordinate regulation of gallbladder motor function in the gut-liver axis. Hepatology. 2008;47: 2112-26.

23. Capitaine Y, Sarles H. Action de l'éthanol sur le tonus du sphincter d'Oddi chez l'homme. Biol Gastroenterol (Paris). 1971;3(Suppl. 3):231-5.

24. Pirola RC, Davis AE. Effects of ethyl alcohol on sphincteric resistance at the choledocho-duodenal junction in man. Gut. 1968;9:557-60.

25. Viceconte G. Effects of ethanol on the sphincter of Oddi: an endoscopic manometric study. Gut. 1983;24:20-7.

26. Goff JS. The effect of ethanol on the pancreatic duct sphincter of Oddi. Am J Gastroenterol. 1993;88:656-60. 